\title{
Local Problem Agendas in the Chinese Countryside as Viewed by Cadres and Villagers
}

\author{
M Kent Jennings \\ Department of Political Science, Ellison Hall, University of California, Santa Barbara, Santa \\ Barbara, CA 93016, USA. \\ E-mail: jennings@polsci.ucsb.edu
}

\begin{abstract}
An important question about political linkages in any polity is the degree to which actors at various levels in the political hierarchy have similar policy agendas. This paper addresses that topic by utilizing data from a four-county survey of villagers and officials at the village, township, and county level in the Chinese countryside. With two critical exceptions, officials in general perceived greater problem severity than did villagers. Lower ranking officials saw greater and different problem severity than did higher-ranking ones, especially with respect to economic and infrastructure problems, but county locale outweighed rank in importance. In terms of dyadic congruence, villager agendas were most faithfully reflected in their most proximate but least influential officials, the village leaders. Hierarchical rank, local conditions, and physical proximity are thus key elements affecting perceptions of and agreement about local problem agendas.
\end{abstract}

Acta Politica (2003) 38, 313-332. doi:10.1057/palgrave.ap.5500042

Keywords: Chinese countryside; political agendas; mass-elite congruence; political elites

\section{Introduction}

Local Problem Agendas in the Chinese Countryside As Viewed by Cadres and Villagers

One way of honing in on the political process is to focus on the relationships between individuals at different levels within the political hierarchy. This may involve, for example, linkages between individuals and groups, between individuals and governmental authorities, and between governmental authorities at different levels. A perennially important political question is the degree to which the actors at various levels in the hierarchy have similar policy agendas. The degree of similarity has implications for such varied topics as resource allocation, policy implementation, norms of reciprocity and trust, conflict resolution, and political representation. In this article, I address the issue of concordance regarding the local problem agenda in the Chinese countryside by drawing on a multi-level research design involving villagers and 
local leaders at multiple levels of government. In a departure from most inquiries about congruence across different levels of the political hierarchy, this paper treats congruence among local elites according to governmental level as well as the more customary topic of congruence between leaders and ordinary citizens. Since there is little or no systematic literature available with respect to the former topic, either in China or elsewhere, the elite analysis will be largely exploratory. ${ }^{1}$

Although decision-making in China is typically portrayed as a top-down model, much of the implementation of domestic policies occurs at the local level and is administered by local officials. Localities tend to have considerable discretion in the implementation of policies, especially given the vastness of the nation as well as recurrent struggles between the periphery and the Centre. If anything, the dramatic economic reforms and modest political reforms ushered in during the Deng Xaio Ping era have enhanced the discretion and initiative of local officials. These changes have highlighted in particular the various duties and resources of the cadres at each level and the potential for cross-level cooperation as well as competition (Brugger and Reglar, 1994, chapter 3; Oi, 1999, chapter 4). County, township, and village officials in China exist in a hierarchical order, although with considerable interdependence among them. Technically, villages are not an official level of government, a distinction that will be ignored here because villages function, in effect, as a governmental tier and - along with the townships - have been the locus of much economic and (limited) political reform.

The degree of cross-rank congruence among cadres regarding local problems presumably has a bearing on the formulation and implementation stages of policymaking (e.g., Bernstein and Lu, 2000). Local governance should proceed more smoothly if cadres at different ranks have similar views about the problem agenda and present a common front to the mass public. Conversely, dissimilarity portends friction and difficulties in problem solving. Moreover, the degree of agreement across the three levels of local leadership has implications for the degree of agreement between ordinary folks and their leaders at these three different levels. High degrees of cross-rank cadre concordance within a given political area imply little differentiation in citizenry-cadre agreement according to cadre rank; low degrees leave open the possibility that villagers achieve 'better' representation at some levels than at others.

That topic, congruence between villagers and their local leaders at different levels, forms the second analytic focus of this paper. Here the extant literature provides a firmer anchor. A key issue from a normative standpoint is the degree to which the leaders - as the advantaged in an asymmetrical power relationship - share the preferences of the led. Although legitimate and persuasive reasons can be offered by leaders for departures from shared 
preferences, the democratic norm is that there ordinarily be at least a modicum of concurrence between leaders and the led (Pitkin, 1967, 209-210). Beyond the normative aspects, all else equal, shared preferences would also be expected to accompany higher governmental performance and citizen satisfaction as well. Studies of mass-elite linkages in western democracies have included matching the preferences of such specific mass-elite combinations as political party convention delegates and the party rank and file (e.g., Kirkpatrick, 1976; Miller and Jennings, 1986); community leaders and community residents (e.g., Hansen, 1975; Verba and Nie, 1972); school board members and their constituents (Zeigler and Jennings, 1974); and - most commonly — legislative representatives and their constituents (e.g., Miller and Stokes, 1963; Barnes, 1977; Kuklinski, 1978; Converse and Pierce, 1986; Esiasson, 1999; Hill and Hurley, 1999; Holmberg, 1999). ${ }^{2}$ Structural as well as personal characteristics have been found to affect the levels of concordance between masses and elites. As Communist and former Communist systems turn toward forms of political representation with potential electoral sanctions and more grass-roots involvement, the topic of concordance between elites and masses has acquired new relevance and has become more amenable to empirical inquiry (e.g., Miller et al., 1997).

Investigations of this type in China will almost necessarily be confined to the local level as of now, because it is there that political reforms affecting issues of representation have been most pronounced, most singularly in the rural areas. ${ }^{3}$ Beginning in the early 1980s, a number of official pronouncements were issued, including the 1987 Organic Law of Villagers' Committees, that were designed to strengthen and democratize village autonomy. Subsequently, competitive local elections have increased though at uneven rates and in diverse modes ( $\mathrm{Li}$ and O'Brien, 1999; Pastor and Tan, 2000); the role of villagers' committees and assemblies has been elevated though with uncertain consequences (e.g., Oi and Rozelle, 2000; O'Brien, 2002a, b), and villagers are beginning to use reform principles in the cause of combatting local authorities (e.g., Jacobs, 1991; O'Brien, 1996; Epstein, 1997; Shi, 1999). Given these developments, it will be instructive to explore concordance between villagers and their leaders during this time of transition so that it may serve as a baseline for future unfoldings.

In what follows I use a multi-county, multi-level sample of local cadres and villagers to address three questions. First, what are the aggregate similarities between villagers and officials as a whole as they view local problems, and how do these vary by problem area and locality? Second, to what degree is cadre rank related to the perception of local problems and how does locality affect that relationship? Third, how does concordance between local officials and the villagers with whom they are directly linked vary by problem area, cadre rank, and locality? ${ }^{4}$ 


\section{A Multi-level, Integrated Research Design}

These questions will be addressed with data based on field research carried out in the spring of 1990. The first stage of the nested sampling design consisted of a purposive selection of four countryside counties distributed across four provinces - Anhui, Hebei, Hunan, and Tianjin. ${ }^{5}$ These counties met the criteria of variation according to province, economic structure, proximity to urban centres, and population size. In order to draw a probability sample of villagers, the townships within each county were first stratified by urban-rural character and per capita income. Five townships (plus the county seat) within each county were selected, with the probability of selection being proportionate to size (pps). At the next stage, three administrative villages were selected from each of the five townships on a pps basis. The final stage of selection consisted of drawing systematic samples of 20-25 individuals, aged 18 years and over, at the village level. Student interviewers from Peking University obtained 1270 usable interviews spread rather evenly across the four counties, for an unadjusted response rate of $77 \%$. Non-response was almost completely a function of incorrect household listings or the physical absence of the intended respondents.

A second set of survey data consisted of interviews with local officials, who - for purposes of variety - shall also be referred to as cadres, leaders, and elites. The sample of leaders was designed to include diversity and to maximize the potential for mass-elite comparisons. To that end, the sample consisted of the single head or leader at the village level, the Communist Party secretary and government head (or deputies thereof) at the township level, and the top-level generalist and functionally specialized leaders at the county level. Altogether, interviews were held with 252 leaders, divided between 59 at the village level, 48 at the township level and 145 at the county level. ${ }^{6}$

Two desirable aspects of measures used in comparing preferences across different levels within a political hierarchy are that they have substantive, realworld implications and that they cover subject matter about which both officials and ordinary citizens will have some views. Perceptions regarding the presence and severity of local problems meet both criteria. Local problems are likely to be common currency in both formal and informal communication flows in the Chinese countryside. As will be demonstrated below, most people can retrieve at least rudimentary experiential evidence when making judgements about the prevalence of given problems. As concrete rather than abstract phenomena, local problems can serve not only as the sources of disgruntlement and unresolved conflicts but also as the bases of individual and collective political action, both conventional (e.g., Jennings, 1996; O'Brien, 1996) and unconventional (e.g., Bernstein and Lu, 2000; Liu, 1996; O'Brien, 2002a, b). Indeed, one of the motivating factors in the top-down encouragement of local 
reform was to facilitate more consonance between local officials and the citizenry about policy implementation and the handling of local problems (e.g., Epstein, 1997; Kelliher, 1997; Howell, 1998; Shi, 1999).

In order to make direct comparisons between officials at different levels and between officials and the villagers regarding their perceptions about local problems, all respondents were presented with a 13-item battery that began with, 'Do you think any of the following are problems in this area?'7 Affirmative answers were followed by, 'Do you think this is a very serious problem here, serious, or not serious?' The problems listed were, in order: dayto-day supply of goods, medical care, income distribution, education, prices, public order, birth control, supply of energy resources, transport and communications, protection of the environment, equality of the sexes, industrial development, and agricultural development. In contrast to some topics addressed in Chinese surveys, which are plagued by large amounts of missing data among general populations (Shi, 1996; Zhu, 1996), the problems battery had a very low 'don't know' rate among the villagers and essentially no missing data at all among local leaders. ${ }^{8}$ Elites and rank and filers may, as shall be seen, have different perceptions, but the concept of local problems as a response stimulus falls within the cognitive grasp of virtually all respondents. ${ }^{9}$

\section{Aggregate Comparisons}

It will be instructive to look initially at the aggregate distributions of problem designations by county and by rank and filers compared with leaders, regardless of rank. ${ }^{10}$ The problem areas have been grouped into two loosely defined subsets, one dealing with infrastructure and economic phenomena, the other with social services and human relations. Not surprisingly, cadres within each county register a higher mean number of perceived problems (Table 1, last row). Since they are representatives of the public charged with fiduciary responsibilities and with presumably more encompassing perspectives, the cadres 'should' be conscious of more problems. With the glaring and politically charged exceptions of prices and supply of goods, cadres also designated all the specific problems more often $(P<0.05$ or better on virtually all comparisons). Goods for agricultural purposes or village and township enterprises are often in short or unpredictable supply, and these goods are also often seen as costly and subject to the politics of local corruption (e.g., Oi, 1989). ${ }^{11}$ In these two instances involving immediate economic difficulties, then, villager frustration outweighs cadre breadth of perspective.

Even a casual inspection of the overall results also indicates striking variations in problem perceptions according to county. A more systematic treatment, based on analysis of variance, revealed strong cross-county variance 
Table 1 Perceptions of local problems among villagers and all cadres, by county (in percent)

\begin{tabular}{|c|c|c|c|c|c|c|c|c|c|c|c|c|}
\hline & \multicolumn{12}{|c|}{ County } \\
\hline & \multicolumn{3}{|c|}{$A$} & \multicolumn{3}{|c|}{$B$} & \multicolumn{3}{|c|}{$C$} & \multicolumn{3}{|c|}{$D$} \\
\hline & Villager: & 1 ll cadres & Difference & Villagers & All cadres & Difference & Villagers & All cadre & Difference & Villager & ll cadre & Difference \\
\hline \multicolumn{13}{|c|}{ Infrastructure and economics } \\
\hline Prices & 81 & 61 & -20 & 82 & 56 & -26 & 83 & 73 & -10 & 57 & 37 & -20 \\
\hline Supply of goods & 42 & 23 & -19 & 49 & 30 & -19 & 28 & 20 & -8 & 18 & 14 & -4 \\
\hline Energy resources & 77 & 62 & -15 & 52 & 81 & +29 & 36 & 60 & +24 & 30 & 60 & +30 \\
\hline Transp. \& commun & 10 & 18 & +8 & 22 & 43 & +21 & 17 & 23 & +6 & 7 & 18 & +9 \\
\hline Agricult. develop. & 49 & 23 & -26 & 44 & 48 & +4 & 27 & 33 & +6 & 16 & 60 & +44 \\
\hline Industrial develop. & 42 & 70 & +28 & 44 & 80 & +36 & 48 & 48 & 0 & 39 & 55 & +16 \\
\hline Income distrib. & 18 & 41 & +23 & 40 & 44 & +4 & 31 & 48 & +17 & 26 & 39 & +13 \\
\hline \multicolumn{13}{|c|}{ Social services and human relations } \\
\hline Medical care & 29 & 27 & -2 & 40 & 62 & +22 & 31 & 56 & +25 & 25 & 47 & +22 \\
\hline Education & 35 & 62 & +27 & 40 & 64 & +22 & 45 & 66 & +21 & 17 & 36 & +19 \\
\hline Environment & 12 & 16 & +4 & 23 & 47 & +24 & 12 & 47 & +35 & 14 & 40 & +26 \\
\hline Public order & 25 & 27 & +2 & 67 & 77 & +10 & 22 & 27 & +5 & 17 & 31 & +14 \\
\hline Birth control & 24 & 56 & +32 & 28 & 61 & +33 & 24 & 77 & +53 & 12 & 26 & +14 \\
\hline Sex equality & 7 & 19 & +8 & 12 & 17 & +5 & 8 & 28 & +20 & 7 & 14 & +7 \\
\hline Mean number & 4.0 & 5.0 & +1.0 & 4.9 & 7.0 & +2.1 & 3.6 & 6.1 & +2.5 & 2.6 & 4.8 & +2.2 \\
\hline
\end{tabular}


among both villagers and cadres: $P<0.001$ on nine of the 11 problems and $<0.05$ on two for the villagers; and $P<0.001$ on eight problems and $<0.01$ on one for the cadres. That is, significant differences exist across the counties independent of the variances within each county. Not surprisingly, even stronger cross-unit variance was found at the lower, more highly differentiated levels of the townships and villages in which the villagers were located $(P<0.001$ in all instances $){ }^{12}$ Not surprisingly, then, the profile of the problem agenda proves to be highly susceptible to location. This variance, while important in a substantive sense, also facilitate the statistical approach that will be taken in a later section dealing with concordance between local leaders and followers.

Although the findings reported in Table 1 offer an overall picture of problem agenda agreement at the aggregate level, they obscure two key elements. First, no distinctions were made among the cadres according to governmental level. There are reasonable grounds, described below, for suspecting that local cadres will define the problem agenda differently according to their structural rank. Second, and relatedly, the villagers and cadres as a whole were being compared within each county. Yet the villagers are linked to cadres at three different levels in a series of dyadic combinations. Again, as outlined below, there are reasons to expect different levels of congruence between leaders and the led according to cadre level. Moreover, this requires linking up, in dyadic fashion, villagers and their leaders at the three different levels. We turn first to a comparison of cadres within each county.

\section{Variations According to Cadre Rank}

Contrasting expectations exist as to whether cadre perceptions of local problems would differ by rank - village, township, or county. As position in the hierarchy rises, the level of formal training increases, the geographical scope of responsibility broadens, and the access to information sources, including personal networks, expands. These considerations suggest greater problem recognition as cadre rank rises. On the other hand, proximity to local conditions varies enormously according to cadre rank. Whereas village leaders live in the proximate environment for which they are 'responsible,' township and especially county leaders necessarily live either in sites that are less proximate or occupy positions for which residential site is essentially irrelevant. Unlike county and township leaders, village leaders are ordinarily locals and are not rotated geographically. These features suggest greater problem recognition by the village leaders.

Working against any cross-rank contrasts are three other factors. One is that of referent. The volume of cross-rank disagreement would diminish to the 
degree that most cadres, regardless of level, have a similar spatial referent in mind when thinking about local problems. A second constraint would exist if the problem areas are in fact fairly uniformly distributed throughout the county. If energy resources are a problem for most every village, then it is a problem for every township, and the entire county - and would probably be perceived as such. A third consideration is the official line on what problems dominate the local problem agenda. Commitment to such pronouncements with respect to particular problems might be echoed at each cadre level, thereby mitigating 'true' differences in beliefs.

It will be recalled that respondents were asked to adjudge the severity of the problems that they identified. In order to incorporate intensity into the problem designation measures, these follow-up answers were used to construct a four-category variable for each problem that runs from 0 , no, not a problem, up to 3 , yes, a very serious problem. These measures constitute the dependent variables in the following correlation analysis. ${ }^{13}$ The independent variable consists of ordering the cadres according to rank, from village, to township, to county level (scored 0-2). Positive signs mean that the higher the cadre level, the more severe the problem is perceived to be. The lack of significant relationships means relative similarity across the three levels. Note that this procedure assumes linear-like relationships. Analysis of variance confirmed that all the statistically significant results to be reported do in fact rest on linear-like patterns, whereas none of the nonsignificant relationships achieve significance using nonlinear tests.

As Table 2 demonstrates, cadre rank has highly variable predictive power. Although fewer than half of the coefficients achieve statistical significance, sizeable cadre differences emerge in at least one county on all issues except energy supply and medical care. And cadres differ among themselves in three counties with respect to at least four problem areas. In general, cross-rank disagreement runs proportionately higher for problems in the infrastructure/ economics domain $(46 \%)$ than in the social services and human relations cluster $(25 \%)$. Problems associated with tangible, material goods yield more noncongruence. Contrary to the hypothesis that more problem recognition would accompany higher rank, just the opposite prevails for 11 of the 16 significant coefficients, as the negative signs indicate. Especially noticeable are the strong negative coefficients for prices and the supply of goods in three of the counties. Only income distribution and the environment come closest to meeting the expectation that perceived problem severity increases with rank, with positive signs two counties.

On balance, then, physical proximity, and what that implies in terms of general knowledge, empathy, or forthrightness, leads to more problem concerns than does expertise and a larger political unit perspective. Even that generalization needs amending, though, because County D runs counter to the 
Table 2 Correlation between cadre rank and perceptions of problem severity, by county

\begin{tabular}{|c|c|c|c|c|}
\hline & \multicolumn{4}{|c|}{ County } \\
\hline & $A$ & $B$ & $C$ & $D$ \\
\hline \multicolumn{5}{|c|}{ Infrastructure and economics } \\
\hline Prices & $-0.32^{*}$ & $-0.55^{* * *}$ & $-0.51 * * *$ & -0.21 \\
\hline Supply of goods & $-0.59^{* * *}$ & $-0.53^{* * *}$ & $-0.39^{* * *}$ & 0.10 \\
\hline Energy resources & -0.21 & 0.12 & 0.16 & -0.04 \\
\hline Agricult. develop. & $-0.29^{*}$ & $-0.55^{* * *}$ & -0.11 & 0.24 \\
\hline Industrial develop. & -0.24 & -0.05 & $-0.55 * * *$ & -0.01 \\
\hline Income distrib. & $0.35^{* *}$ & 0.21 & 0.21 & $0.39^{* *}$ \\
\hline \multicolumn{5}{|c|}{ Social Services and human relations } \\
\hline Medical care & 0.05 & -0.21 & 0.05 & 0.08 \\
\hline Education & 0.08 & -0.09 & $-0.40 * * *$ & -0.09 \\
\hline Environment & -0.06 & 0.06 & $0.51 * * *$ & $0.48^{* * *}$ \\
\hline Public order & -0.10 & $-0.31^{*}$ & 0.21 & 0.04 \\
\hline Birth control & 0.21 & 0.24 & -0.02 & $0.26^{*}$ \\
\hline
\end{tabular}

Entries are product-moment correlation coefficients. Negative signs indicate an inverse relationship between cadre level and perceived problem severity. Base $N$ 's range from 62 to 64 across the four counties. ${ }^{*} P<0.05 ;{ }^{* *} P<0.01 ; * * * P<0.001$.

pattern. All three of the significant associations in that county are positive higher rank produces more concern about specific problems. In addition, County $\mathrm{D}$ registers the only strong connection between rank and total number of problems cited $(r=0.38, P<0.01)$, as well as having the fewest significant differences. Just why the cadres of County D behave in a different fashion is not readily apparent. Conceivably, the distinctiveness rests in unique environmental conditions or in aspects of the local cadre system that would only be uncovered by detailed fieldwork.

It was proposed above that cross-rank disagreements might be minimized for problems characterizing the county taken as a whole entity. Correspondingly, the fact that a majority of the entries in Table 2 were nonsignificant especially when laid against the substantial cross-county variations among the cadres as a whole shown earlier in Table 1 - suggests that cadre rank and county should be considered simultaneously in order to sort out the importance of each. This was accomplished by constructing two dummy variables for cadre rank: village cadre $(0-1)$ and county cadre $(0-1)$. Township becomes the omitted or baseline category. Similarly, three county dummy variables were constructed, with County A being the omitted category. The problem variables were then regressed against the five dummy variables, using OLS. Table 3 presents the results. 
Table 3 Impact of cadre rank and county on perceptions of problem severity

\begin{tabular}{|c|c|c|c|c|c|c|c|}
\hline & \multicolumn{7}{|c|}{ Country } \\
\hline & Village cadre & Country cadre & $B$ & $C$ & $D$ & Constant & $R^{2}$ \\
\hline \multicolumn{8}{|c|}{ Infrastructure and economics } \\
\hline Prices & $0.85^{* * *}(0.18)$ & $-0.23(0.16)$ & $0.19(0.17)$ & $0.38 *(0.17)$ & $-0.42 *(0.17)$ & $1.93 * * *(0.17)$ & 0.24 \\
\hline Supply of goods & $0.75 * * *(0.13)$ & $-0.03(0.11)$ & $0.07(0.12)$ & $-0.10(0.12)$ & $0.25 *(0.12)$ & $1.27 * * *(0.12)$ & 0.20 \\
\hline Energy resources & $-0.01(0.19)$ & $0.01(0.17)$ & $0.49 * *(0.18)$ & $-0.15(0.18)$ & $-0.20(0.18)$ & $2.18 * * *(0.18)$ & 0.07 \\
\hline Agricult. develop. & $0.16(0.16)$ & $-0.21(0.14)$ & $0.52 * * *(0.16)$ & $0.14(0.16)$ & $0.65 * * *(0.16)$ & $1.42 * * *(0.16)$ & 0.11 \\
\hline Industrial develop. & $0.32(0.18)$ & $-0.17(0.16)$ & $0.62 * * *(0.17)$ & $-0.33 *(0.17)$ & $-0.17(0.17)$ & $2.12 * * *(0.17)$ & 0.16 \\
\hline Income distrib. & $-0.48 * *(0.15)$ & $0.10(0.13)$ & $-0.06(0.14)$ & $0.10(0.14)$ & $-0.10(0.14)$ & $1.66^{* * *}(0.14)$ & 0.10 \\
\hline \multicolumn{8}{|c|}{ Social services and human relations } \\
\hline Medical care & $0.02(0.05)$ & $0.05(0.13)$ & $0.52 * * *(0.13)$ & $0.32 *(0.14)$ & $0.21(0.14)$ & $1.46^{* * *}(0.14)$ & 0.05 \\
\hline Education & $0.18(0.17)$ & $-0.10(0.14)$ & $0.13(0.15)$ & $0.08(0.16)$ & $-0.47 * *(0.16)$ & $1.95 * * *(0.17)$ & 0.09 \\
\hline Environment & $-0.14(0.14)$ & $0.34 * *(0.17)$ & $0.43 * * *(0.13)$ & $0.50 * * *(0.13)$ & $0.36 * *(0.13)$ & $1.05 * * *(0.13)$ & 0.14 \\
\hline Public order & $0.20(0.19)$ & $-0.18(0.16)$ & $1.36^{* * *}(0.17)$ & $-0.01(0.17)$ & $0.00(0.17)$ & $1.49 * * *(0.17)$ & 0.29 \\
\hline Birth control & $-0.30 *(0.16)$ & $0.03(0.14)$ & $0.21(0.14)$ & $0.49 * * *(0.15)$ & $-0.54 * * *(0.15)$ & $1.87 * * *(0.15)$ & 0.20 \\
\hline
\end{tabular}

Entries are unstandardized regression coefficients, with standard errors in parentheses. $P<0.05-0.10 ; * * P<0.01 ; * * * P<0.001$. 
Taking up the effects of cadre level first, the rank of village leader is clearly more consequential than that of county leader (relative to the township leader baseline). Being a village cadre is positively associated with attaching more importance to prices and the supply of goods. By contrast being a village leader is negatively related to the issues of income distribution and birth control. These results underscore those presented in Table 2, but they also extend them. The additional information rests in the fact that these differences hold in the face of substantial inter-county differences, as demonstrated earlier in Table 1. As for the impact of the county cadre variable, the only significant coefficient occurs with respect to protecting the environment. The positive sign here may reflect a general call from central authorities to be more concerned about environmental effects, plus the probable tendency of the most proximate local leaders to emphasize economic development over environmental consequences.

These variations by cadre rank notwithstanding, the consequences of location loom even larger. Not surprisingly, county tends to be most consequential where the cadre rank is less so. Perceptions of problem severity concerning industrial development, energy resources, environmental protection, public order, medical care, and education are strongly associated with one or more counties. Location dominates rank on these sorts of problems. One reason for this dominance is that most or all of these problem areas do, in fact, reflect more countywide phenomena and responsibility than do the other areas. Issues involving medical care and education, for example, typically extend throughout a county and would presumably be recognized as such regardless of cadre rank. Issues such as the supply of goods tend to be more proximately configured and are often subject to arbitrariness on the part of village and township officials.

\section{Dyadic Concordance between Villagers and Cadres}

With aggregate comparisons and cadre differences as a background, we can now address the key issue of congruence between particular villagers and their particular leaders. There are three basic ways of establishing dyadic congruence or representation. Proximity indicates the 'nearness' of the representative to the citizenry mean; centrism examines the degree to which the representative minimizes the distance from this mean; and responsiveness posits that representatives respond to mean (or other) shifts in constituency opinions (Achen, 1978). The present analysis uses responsiveness, which relies on regressing leader scores against those of their constituents.

This procedure, which captures relative rather than absolute congruence, is intuitively appealing and has been used in other contexts (e.g., Miller and Stokes, 1963; Zeigler and Jennings, 1974; Converse and Pierce, 1986; Herrera 
et al., 1992). In the present case, for example, leader and villager scores on problem recognition could move up and down across jurisdictions in high relative fashion while at the same time exhibiting sizeable absolute differences within each jurisdiction. As critics have pointed out, however, using correlation and regression techniques are suspect when the same instrumentation has not been applied to both leaders and followers and when variance is lacking across the territorial units under observation. Fortunately, the data at hand overcome both of those impediments. First, the instrumentation was identical for the cadres and the villagers. Second, as described earlier (see note 12), the variance in problem designations by villagers and cadres at each level of government was substantial, even at the county level.

Regressing leader perceptions against villager perceptions means assuming that villagers influence their leaders, either directly or indirectly. Such expectations about dyadic correspondence based on models involving potential sanctions that villagers might exert on their leaders are problematic in the case at hand. Nevertheless, it will be useful to proceed initially on the assumption that linkage does occur, that information and influence flow upward as well as downward. Although the Chinese countryside has moved only recently toward Western conceptions of representative government, even the cherished ideal of 'the mass line' should carry at least a modicum of normative commitment for local leaders to listen and respond to the rank and file, party supremacy notwithstanding.

Villagers are most proximate to their village leaders in a spatial sense, but they are also governed in both a direct and indirect sense by officials at the township and county levels. Even though the connections between villagers and their township and county officials are more remote than those between them and their village officials, it does not necessarily follow that township and county officials will be more attitudinally remote in terms of any given local problem. Shared outlooks can easily occur without elements of political reform or physical propinquity, though suggestive evidence that political reform does make a difference at the village level will be introduced below. With these considerations in mind, it thus becomes important to look at congruence between followers and leaders at different levels of local government.

The nested design of the study allows for three levels of dyadic analysis. Village leaders can be paired up with their village residents, township leaders with their residents, and county leaders with their residents. Of course, these residents, but not the cadres, are the same individuals and appear in every pairing, but they are aggregated to successively higher levels. In order to compare problem designations by officials and their 'constituents' at each of the three levels, mean scores for the mass public were calculated for each village, township, and county. Each of the 59 different village leaders is, consequently paired up with his village mean score, each of the 48 township 
leaders with their own township means, and each of the 145 county leaders with their own county means. Thus, the units of analysis (dyads) vary from a low of 48 at the township level to a high of 145 at the county level.

Since multiple leaders exist at the township and county levels, only the village level fits the classic single leader/follower model employed in the United States and other single-member district representation systems. The Western electoral analogue for treating the cadres on an individual basis at these higher levels is that of districts with multiple elected representatives, such as at-large city councils, school boards, or parliaments with multi-member districts.

Table 4 shows the dyadic relationships at the county, township, and village levels. Assuming a causal flow from the citizenry to cadres, the cadre scores for each problem were regressed against the mean scores of the relevant political units. The resulting unstandardized $(b)$ coefficients and their accompanying standard errors are shown in the first two columns under each political unit heading. Shown in the third column are product moment coefficients $(r)$, which represent the joint association between cadre and villager scores without assuming directionality.

Several tendencies emerge. With occasional exceptions, as discussed below, congruence runs higher at the village level than at the other two. All the signs

Table 4 Association between villagers' and cadres' perceptions of local problem severity, at three levels

\begin{tabular}{|c|c|c|c|c|c|c|c|c|c|}
\hline & \multicolumn{3}{|c|}{ Country } & \multicolumn{3}{|c|}{ Township } & \multicolumn{3}{|c|}{ Village } \\
\hline & $b$ & $S E$ & $r$ & $b$ & $S E$ & $r$ & $b$ & $S E$ & $r$ \\
\hline \multicolumn{10}{|c|}{ Infrastructureand economics } \\
\hline Prices & $0.58^{*}$ & 0.26 & 0.18 & $0.76^{*}$ & 0.40 & 0.27 & $0.96^{* *}$ & 0.33 & 0.36 \\
\hline Supply of goods & -0.16 & 0.19 & -0.07 & 0.44 & 0.28 & 0.23 & $1.18 * *$ & 0.38 & 0.39 \\
\hline Energy resources & -0.06 & 0.22 & -0.03 & $0.74^{*}$ & 0.32 & 0.32 & 0.51 & 0.30 & 0.22 \\
\hline Agricult. develop. & $-1.5^{* * *}$ & 0.23 & -0.39 & -0.42 & 0.47 & -0.13 & 0.37 & 0.44 & 0.11 \\
\hline Industrial develop. & 0.10 & 0.78 & 0.01 & 0.76 & 0.64 & 0.17 & $1.28 * * *$ & 0.31 & 0.48 \\
\hline Income distrib. & 0.04 & 0.49 & 0.01 & 0.90 & 0.64 & 0.20 & $0.52 *$ & 0.26 & 0.26 \\
\hline \multicolumn{10}{|c|}{ Social services and human relations } \\
\hline Medical care & 0.89 & 0.55 & 0.14 & -0.19 & 0.62 & -0.05 & $0.91^{*}$ & 0.43 & 0.27 \\
\hline Education & $0.87 * *$ & 0.30 & 0.24 & -0.15 & 0.48 & -0.05 & $0.90^{* *}$ & .31 & 0.36 \\
\hline Environment & -0.03 & 1.07 & 0.00 & 0.29 & 0.48 & 0.09 & $0.64^{*}$ & 0.37 & 0.22 \\
\hline Public order & $1.06^{* * *}$ & 0.17 & 0.46 & $1.41 * * *$ & 0.34 & 0.52 & $1.36^{* * *}$ & 0.29 & 0.52 \\
\hline Birth control & $2.76^{* * *} *$ & 0.61 & 0.36 & $3.17 * * *$ & 0.71 & 0.55 & 0.56 & 0.46 & 0.16 \\
\hline
\end{tabular}

The $b$ entries are unstandardized coefficients regressing cadre scores against the relevant political unit means. All of the problem variables run from 0 to 3 . $N$ 's vary from 139 to 142,46 to 47 , and 56 to 58 at the county, township, and village levels, respectively. ${ }^{*} P<0.05-0.10 ; * * P<0.01$; $* * * P<0.001$. 
are positive at that level and all but three of the relationships achieve statistical significance. It is tempting to attribute this outcome to pure chance, in that the likelihood of drawing at random a person from the smaller pool of village residents who resembles other villagers is much greater than the chance likelihood at the more populous township and county levels. That probability is all the more enhanced because village leaders typically emerge from village ranks.

If relative similarity were simply a matter of mathematical probability, the progression would be orderly, with descending scores from village to township to county. As Table 4 shows, however, numerous deviations from this pattern occur, including several instances in which the township dyads clearly have either the highest or lowest levels of congruence. Observe also the notable exception associated with birth control, where concordance runs quite high at the county and township levels and shrinks to insignificance at the village level. ${ }^{14}$ Regardless of the causal mechanisms, however, the point remains that in general the problem agenda of the citizenry is more likely to be reflected in their village leaders than in leaders at higher levels. They are most likely to have their concerns expressed by their most proximate, but least influential, leaders.

As for substantive problems, statistically significant concordance is reached at all governmental levels for only two topics, public order and prices, and at two levels for birth control and education. On average, villagers have a reasonably good chance of having their own priorities echoed among cadres on these four topics. Or, from a top-down perspective, cadres have less need to convince the villagers about the severity of these problems.

At the same time, there are some dramatic departures from anything like cross-level similarity. In addition to the birth control example cited above, mass public means are strongly and negatively associated with cadre assessments at the county level with respect to agricultural problems while being insignificant at the other two. Juxtaposed against that incongruity sits the very strong positive association at the village level for industrial development, whereas little exists at the other two. Or consider energy resources, wherein only the township dyads reach statistically significant levels of agreement. These instances highlight the decidedly variable nature of concordance at multiple levels and caution against generalizations based on a small range of political objects or on only one level of political institutions.

It is beyond the scope of this paper to explore thoroughly the question of what sorts of local characteristics condition levels of dyadic correspondence. Owing to the small $N$ (i.e., only four counties and 24 townships) many variables problem, an examination of this question is necessarily confined to leader-follower dyads at the village level. One very intriguing piece of evidence, 
of particular relevance to the place of political institutions, comes from looking at congruence levels according to the progress of electoral reform. By 1990, Chinese rural areas had begun moving, in very uneven fashion, toward a more open, participative electoral process, one that establishes a more prominent role for ordinary citizens. Such movements, in principal, should make village leaders more sensitive to the voices of the masses. To test this proposition, the villages were divided into those that appeared to be further along on the road toward electoral reform $(N=26)$ than were others $(N=33)$ as of $1990 .^{15}$

Although this measure is rather crude and of unknown reliability, quite suggestive results emerge when dyadic correspondence is examined for the two different sets of villages. Taking agreement on the total number of problems cited, for example, reveals a correlation $(r)$ of $0.51(P<0.01)$ for 'reformed' dyads compared with 0.19 (NS) for the 'unreformed' villages. Similarly, while villager-cadre correspondence was significantly $(P<0.05)$ associated with perceived severity for six of the specific problem areas in the reform villages, the same was true for only one of the unreformed. ${ }^{16}$ These results speak directly to the tendency for mass-elite congruence to be higher at the village than at other levels. Based on these results, it seems clear that the common socialization and environment alone cannot account for the fact that cadre-villager dyadic congruence is much more pronounced at the village than at higher levels. Structural and institutional factors are seemingly at work also.

Of course, it is possible that such differences signify some other property of the village that is the 'real' distinguishing feature or that what leads to concordance also leads to more electoral reform. However, partitioning the dyads according to promising villager and village leader characteristics failed to show results anywhere near those resting on the degree of electoral progress. Nor was the reform variable systematically linked to other likely predictors of congruence. Additional support for the proposition that reform makes a difference comes from Manion's (1996) analysis from the same project. Using centrism as the indicator of congruence, she demonstrated in a multivariate analysis that greater electoral competitiveness across villages yielded higher congruence between village leaders and the citizenry with respect to attitudes about the state's role in the economy. Taking all these results into account, it appears that participatory democracy does, in fact, make a difference.

\section{Conclusion}

Designations of local problems have provided an ideal vehicle for assaying congruence between different layers in the local political hierarchies of rural China. The range of concerns was wide and both villagers and leaders could 
make judgements about whether particular problems existed in their areas. Although a few problems loomed large in all four counties surveyed here, the heterogeneity across counties was striking. Leaders tended to perceive more problems than did their followers, with two important qualifications. One is that villagers in all four counties exceeded their leaders' concerns with respect to two topics of perennial salience and anxiety in rural China - prices and the supply of goods. A second is that village heads, those most proximate to day to day village life, tended to be more troubled about local issues than were higher level cadres, especially with respect to infrastructure and economic problems. Although agreement between villagers and their particular leaders (dyadic congruence) varied considerably across topics and locales, villagers most often found their priorities echoed in their own village heads, their closest but least influential leaders. Further analysis suggested that this congruence was strongly affected by the level of electoral reform in the village.

The results presented in this paper show that political linkages in the Chinese countryside — and by extension in other domains as well — are vitally affected by what political strata are being analyzed, by the research sites chosen, and by variable selection. Conclusions about congruence within political hierarchies depend not only on the substantive topic at hand, but also on the cross-level comparisons being made. Taking into account three cadre levels, for example, revealed considerable disagreement as well as consensus across ranks, with attendant implications for relationships across the three political levels. By the same token, the inclusion of sub-county leaders demonstrated that the weak dyadic similarity found at the county level was counteracted by reasonably strong ones at the lower, most keenly so at the village level. Including officials at all three levels and pairing them up with their relevant constituents demonstrated a fundamental point about studying political linkages: aggregation matters and it matters importantly.

The frequent disparate results across the four counties illustrate the perils of single site inquiries. Such inquiries can yield more in-depth understanding of local conditions, which would have been valuable for unravelling some idiosyncrasies in the present study. The downside, of course, is the danger of drawing unwarranted inferences. With respect to variable selection, consider that even within the scope of the problem agenda, wide variations emerged depending upon the particular problem at hand.

Finally, these results show the importance of taking into account possible mediating effects when examining linkages and cross level relationships. Mediating effects could be detected as a result of the study design itself, with its nested sampling scheme and inclusion of three cadre ranks. Where people live and what position they occupy in the political stratification system make a difference. One example of conditioning effects with particular relevance to democratic theorists appeared took the form of analyzing the villages 
according to early electoral reform progress. Mass-elite congruence seemingly prospered in those villages having such involvement.

\section{References}

Achen, C. (1978) 'Measuring representation', American Journal of Political Science Vol 3, 22(August): 475-510.

Barnes, S.H. (1977) Representation in Italy: Institutionalized Tradtion and Electoral Choice, Chicago: University of Chicago Press.

Bernstein, T.P. and Lu, X. (2000) 'Taxation without representation: the central and local states in reform China', China Quarterly 163(September): 742-763.

Brugger, B. and Reglar, S. (1994) Politics, Economy, and Society in Contemporary China, Stanford: Stanford University Press.

Chen, J. (1999) 'Comparing mass and elite subjective orientations in urban China', Public Opinion Quarterly 63 issue 2(Summer): 193-219.

Converse, P.E. and Pierce, R. (1986) Political Representation in France, Cambridge, MA: Harvard University Press.

Dickson, B. (2002) 'Do Good Businessmen Make Good Citizens An Emerging Collective Identity among China's Private Entrepreneurs', in M. Goldman and E.J. Perry (eds.) Changing Meanings of Citizenship in Modern China, Cambridge, MA: Harvard University Press, pp. 255-287.

Eldersveld, S.J. and Shen, M. (2001) Support for Economic and Political Change in the China Countryside, Lanham, MD: Lexington Books.

Epstein, A. (1997) 'Village Elections in China: Experimenting with Democracy', in Joint Economic Committee, Congress of the United States (ed.) China's Economic Future, Armonk, NY: M.E. Sharpe, pp. 403-421.

Esiasson, P. (1999) 'Not All Politics Is Local: The Geographical Dimension of Policy Representation', in W.E. Miller et al. Policy Representation in Western Democracies, Oxford: Oxford University Press, pp. 110-136.

Hansen, S. (1975) 'Participation, political structure, and concurrence', American Political Science Review 69(4): 1181-1199.

Herrera, C.L., Herrera, R. and Smith, E.R.A.N. (1992) 'Public opinion and congressional representation', Public Opinion Quarterly 56 issue 2(Summer): 185-205.

Hill, K.Q. and Hurley, P.A. (1999) 'Dyadic representation reappraised', American Journal of Political Science 43 issue 1(January): 109-137.

Holmberg, S. (1999) 'Collective Policy Congruence Compared', in W.E. Miller et al. Policy Representation in Western Democracies, Oxford: Oxford University Press, pp. 87-109.

Howell, J. (1998) 'Prospects for village self-governance in China', Journal of Peasant Studies 25 issue 3(April): 86-111.

Jacobs, J.B. (1991) 'Elections in China', Australian Journal of Chinese Affairs 25(January): 71-99.

Jennings, M.K. (1996) 'Political participation in the Chinese countryside', American Political Science Review 91 issue 2(June): 361-372.

Jennings, M.K. (2001) 'Multi-level Analysis of the Four-County Survey in the PRC', in X. Yongmin and H. Ji (eds.) Level-of-Analysis Effects, Taipei: Weber Publication, pp. 289-326.

Kelliher, D. (1997) 'The Chinese debate over village self-government', The China Journal 37(January): 63-86.

Kirkpatrick, J. (1976) The New Presidential Elite: Men and Women in National Politics, New York: Russell Sage and Twentieth Century Fund.

Kuklinski, J.H. (1978) 'Representativeness and elections: a policy analysis', American Political Science Review 72 issue 1(March): 165-177. 
Li, L. and O'Brien, K.J. (1999) 'The Struggle over Village Elections', in R. MacFarquhar and M. Goldman (eds.) The Paradox of China's Post-Mao Reforms, Cambridge, MA: Harvard University Press.

Liu, A.P. (1996) Mass Politics in the People's Republic: State \& Society in Contemporary China, Boulder, CO: Westview Press.

Manion, M. (1996) 'The electoral connection in the Chinese countryside', American Political Science Review 90 issue 4(December): 736-748.

Miller, A.H., Hesli, V.L. and Reisinger, W.M. (1997) 'Conceptions of democracy among mass and elites in post-Soviet societies', British Journal of Political Science 27 issue 2(April): 157-190.

Miller, W.E. and Jennings, M.K. (1986) Parties in Transition: A Longitudinal Study of Party Elites and Party Supporters, New York: Russell Sage.

Miller, W.E. and Stokes, D.E. (1963) 'Constituency influence in Congress', American Political Science Review 57 issue 1(March): 45-56.

O’Brien, K.J. (1996) 'Rightful resistance', World Politics 49 issue 1(October): 31-55.

O'Brien, K.J. (2002a) 'Villagers, Elections, and Citizenship', in M. Goldman and E.J. Perry (eds.) Changing Meanings of Citizenship in Modern China, Cambridge, MA: Harvard University Press, pp. 212-231.

O'Brien, K.J. (2002b) 'Review essay: collective action in the Chinese countryside', The China Quarterly 48(July): 140-154.

Oi, J.C. (1989) State and Peasant in Contemporary China: The Political Economy of Village Government, Berkeley, CA: University of California Press.

Oi, J.C. (1999) Rural China Takes Off: Institutional Foundations of Economic Reform, Berkeley, CA: University of California Press.

Oi, J.C. and Rozelle, S. (2000) 'Elections and power: the locus of decision making in Chinese villages', China Quarterly 162(June): 513-539.

Pastor, R.A. and Tan, Q. (2000) 'The meaning of China's village elections', China Quarterly 162(June): 490-512.

Pitkin, H.F. (1967) The Concept of Representation, Berkeley, CA: University of California Press.

Shi, T. (1996) 'Survey Research in China', in M.X. Delli-Carpini, L. Huddy and R.Y. Shapiro (eds.) Research in Micropolitics, Vol. V., New Directions in Political Psychology, Greenwich: JAI Press, pp. 213-250.

Shi, T. (1999) 'Village committee elections in China', World Politics 51 issue 3(April): 385-412.

Stimson, J., McKuen, M. and Erikson, R. (1995) 'Dynamic representation', American Political Science Review 89 issue 3(September): 543-565.

Verba, S. and Nie, N.H. (1972) Participation in America: Political Democracy and Social Equality, New York: Harper \& Row.

Weissberg, R. (1978) 'Collective vs. dyadic representation in Congress', American Political Science Review 72 issue 2(June): 535-547.

Zhu, J.-H. (1996) 'I Don't Know' in public opinion surveys in China: individual and contextual causes of item non-response', Journal of Contemporary China 5(July): 223-244.

Zeigler, H.L. and Jennings, M.K. (1974) Governing American Schools: Political Interaction in Local School Districts, North Scituate: Duxbury Press.

\section{Notes}

1 Dickson (2002) conducted an eight-county survey of local entrepreneurs and local cadres, with the latter coming from village, township, and county levels. However, in the cited report all officials are lumped together into the one analytic category of officials. 
2 I refer here only to studies based on coordinated surveys of both masses and elites. A variety of other approaches have been used, especially that of matching public opinion data with policy outputs. See, inter alia, the innovative work by Stimson et al. (1995) with respect to the United States.

3 Chen (1999) compares a sample of the general public and mid-range officials in the Beijing area with respect to political values, but these two sets of respondents are not linked to each other in a functional way.

4 Topics one and three are also addressed in part by Jennings (2001) in a conference symposium.

5 Tianjin is a municipal province. The terms of the research arrangement prohibit listing the names of the four counties. No claims are being made for the national 'representativeness' of these four counties. However, the variations built into their selections and the cross-county similarities with respect to some of the key findings should prove suggestive at the very least. Moreover, any attempt to conduct a nationally representative study with the sort of nested and linked design used here would be exceedingly difficult and exorbitantly expensive.

6 Approximately two-thirds of the village leaders were party branch secretaries who were also serving on the villagers committee; the others were directors of their villagers committee. Local government specialists at Peking University determined 'Top-level' positions at the county level. A majority of these leaders were generalists. All township leaders were interviewed as were all but one of the village leaders and two of the designated county leaders. In the analysis to follow, no distinctions are made between state and party cadres, in part because of the substantial overlap in the two, and in part because preliminary analysis revealed modest and inconsistent differences between the two types for the topics to be addressed in this paper.

7 This question was preceded by one asking the respondents how satisfied they were to be living in the county, thereby priming them to think beyond the village level when identifying problems. Higher level cadres almost certainty thought about wider environs, a point subsequently addressed in the text.

8 The missing data mean for the mass public sample across the 13 questions was 1.3 , and $54 \%$ of the respondents registered absolutely no missing data (don't knows or not ascertaineds).

9 The structured question also avoids the problem of variations in respondent volubility based on using open-ended questions, as was done in Verba and Nie (1972) and in Zeigler and Jennings (1974).

10 Comparisons based on lumping all the cadres together might be considered a rough way of assessing collective representation (e.g., Weissberg, 1978), even though these leaders do not act as collective, decision-making bodies. For another application of aggregate comparisons based on the present study, see Eldersveld and Shen (2001).

11 Although asked in a different format (which precludes exact comparisons with the problem battery), responses to a question about local cadre corruption revealed that villagers in each county saw it as a much more serious problem than did the cadres.

12 For the villager sample the average eta coefficients for the 11 stated problems were $0.21,0.28$ and 0.36 at the county, township, and village levels, respectively. The corresponding coefficients for the total number of problems cited were $0.32,0.37$, and 0.41 . These cross-unit differences, especially at the village level, are somewhat larger than those reported in other studies, where the aggregation levels are higher and the measured objects are issue positions (Converse and Pierce, 1986, chapter 16).

13 Attempts to combine the separate measures into indexes, via factor analysis and other procedures, proved unsuccessful.

14 This counter-intuitive finding appears to reflect in part the ambiguity in perceptions among villagers and village leaders arising from the controversial nature of birth control implementation at the local level and the awkward position in which village leaders often find themselves. 
15 Technically, the distinction was between those villages for whom electoral data simply did not exist at the township department of civil affairs. Manion $(1996,742)$ makes the plausible argument that this distinction reflects the priority, and hence the progress, made toward implementing electoral reform.

16 Using more complete and reliable village reform, data collected subsequent to 1990 showed, if anything, stronger effects. 